Miloš M. Živanović

Control Engineer EDePro Company Belgrade

Mihailo P. Lazarević Professor University of Belgrade Faculty of Mechanical Engineering

\section{Conditions for Dynamic Balance of a Rigid Body With Heavy Foot}

The model of a rigid body and heavy foot joined by the revolute joint in the constant gravitational field is described. The rigid body moves in the vertical plane, whereas the heavy foot lies on the flat, very rough horizontal support. Conditions for the dynamic balance of this system are mathematically expressed by using the ZMP method. It is shown that they determine an area in the phase space in which the state of the system should be in order that its dynamic balance is kept. It is also shown by appropriate simulations of motion of the system in the dynamic balance that these conditions are not sufficient for the system to keep its upright posture, but are in connection with its controllability. It is briefly discussed what are the necessary conditions for this system in dynamic balance to keep its upright posture.

Keywords: dynamic balance, upright posture, zero moment point, controllability, rigid body..

\section{INTRODUCTION}

We consider a rigid body of the mass $m$ joined by the revolute joint to the foot of the mass $m_{\mathrm{f}}$. The foot lies on the flat, horizontal, inertial and very rough support in the constant gravitational field of magnitude $\vec{g}$, Fig. 1 . The system has a dynamically balanced posture at the initial instant, 0 . It means that the zero moment point (ZMP) [2] coincides with the center of pressure (CoP) and both points are in the interior of the support area (the minimal convex surface comprising all contacts between the foot and support). We adopt that the support area is a rectangle.

Let Axyz be the Cartesian orthogonal coordinate frame with units vectors $\vec{i}, \vec{j}$ and $\vec{k}$, which is immobile with respect to the foot and whose coordinate beginning $\mathrm{A}$ is somewhere on the revolute joint axis, Fig. 1.

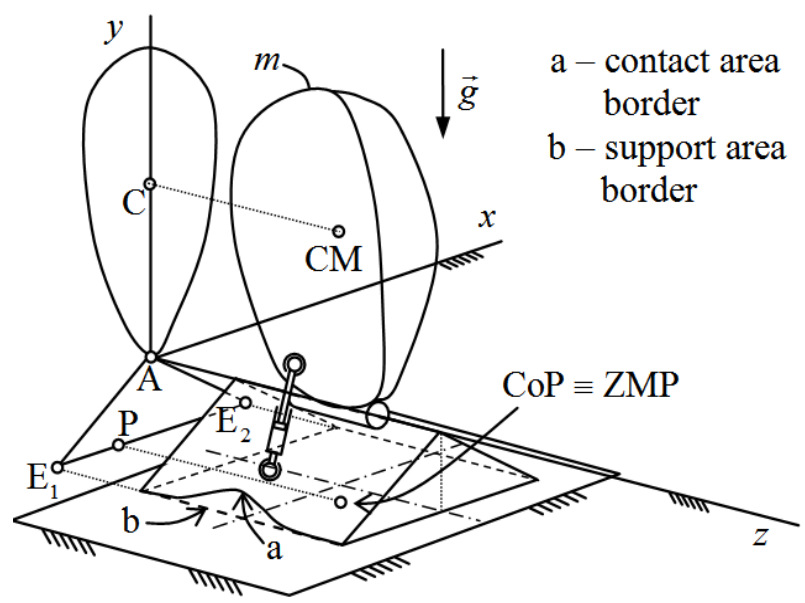

Fig. 1 The rigid body with heavy foot

Received: May 2014, Accepted: December 2014

Correspondence to: Miloš Živanović

EDePRO, Kruzni put bb,

11000 Belgrade, Serbia

E-mail: milanzi@sbb.rs
Control of the rigid body motion is done by the light linear actuator whose one end is connected to the rigid body by a spherical joint, and other to the foot also by a spherical joint. Friction in all joints is neglected. The actuator produces the corresponding reaction force that acts on the rigid body at the place of spherical joint where the rigid body is connected to the actuator. The action of this force reduced to the point $\mathrm{A}$ defines the corresponding torque $\overrightarrow{\mathfrak{M}}$ by which the rigid body motion is controlled. As long as the system posture is dynamically balanced, the foot will be at rest, while the rigid body will rotate around the axis $z$ that is immobile with respect to the support. In this case, among all projections of the torque $\overrightarrow{\mathfrak{M}}$, only the projection

$\mathfrak{M}_{z}=\overrightarrow{\mathfrak{M}} \cdot \vec{k}$ to the axis $z$ affects the rotation of the rigid body. Without loss of generality, we adopt that the projection $\mathfrak{M}_{z}$ can be produced by wish in the corresponding limits. Other two projections $\mathfrak{M}_{x}$ and $\mathfrak{M}_{y}$ are balanced with corresponding projections of torques of the rigid body weight, and static and dynamic reactions [3] in revolute joint, with respect to the point A.

Assumption 1: The torque $-\mathfrak{M}_{y}$, which acts on the foot, can produce slipping of the foot. Since the support is very rough, we shall consider that the foot cannot slip as long as the normal reaction of the support exists.

Assumption 2: The torque $-\mathfrak{M}_{x}$, which acts on the foot, can produce rotation of the foot with respect to the axis $x$. However, we shall consider that the foot is wide enough along the $z$-axis so that the foot cannot start to rotate around axis $x$.

By these assumptions, the dynamic balance can be considered in one of the planes perpendicular to axis $Z$. We choose $x A y$ plane. Now, the definition of the dynamic balance 0 of the rigid body with heavy foot boils down to: 
Dynamic balance: It is said that the rigid body with heavy foot is in dynamic balance if there is no rotation of the foot around any edge of the support area, which is parallel to the axis $\mathrm{z}$,

while the condition for the system to be in dynamic balance 0 to

Condition for dynamic balance: For the dynamic balance, it is necessary and sufficient that the resultant of the normal reaction forces of the support acts at the point whose projection $\mathrm{P}$ along axis $\mathrm{z}$ to the plane $x \mathrm{Ay}$ belongs to the support segment $\overline{\mathrm{E}}_{1} \mathrm{E}_{2}$ (projection of the support area to the plane along z-axis) excluding the segment's edges.

It is obvious that for this system at first glance the state of rest of the foot is equivalent to dynamic balance of the system, since if the foot does not rotate, then it can be moved only vertically upward so that the contact with the support is lost and along with it the sense of the dynamic balance.

In this paper the mathematical model of the rigidbody-with-heavy-foot system in dynamical balance is given, the conditions for the dynamic balance of this system is mathematically formulated, simulation results of the motion of the system in dynamic balance are shown and discussed, and necessary conditions for the system to keep the upright posture are explained.

\section{MATHEMATICAL MODEL OF THE SYSTEM IN DYNAMIC BALANCE. STATIC EQUILIBRIUM OF THE FOOT}

The system in dynamic balance realizes rotation around $z$-axis which is immobile with respect to the support. The system motion is described by the differential equation

$$
J_{\mathrm{z}} \ddot{\varphi}=m g \rho_{\mathrm{C}} \sin \varphi+\mathfrak{M}_{\mathrm{z}},
$$

where $J_{z}$ - moment of inertia of the rigid body with respect to axis $z, \rho_{\mathrm{C}}$ - the magnitude of position vector $\vec{\rho}_{\mathrm{C}}$ of the projection $\mathrm{C}$ of the mass center of the rigid body to the plane $x$ Ay Fig. 1 with respect to the pole A. The positive mathematical direction is taken as the positive direction of the angle $\varphi$.

In order to express the conditions for dynamic balance mathematically, we need to find the reaction force $\vec{R}_{\mathrm{A}}$ of the foot in the joint in $x \mathrm{Ay}$ plane. The reaction is found from the equation of motion of the mass center of the rigid body:

$$
\begin{array}{ll}
m \vec{a}_{\mathrm{C}}=\vec{G}+\vec{R}_{\mathrm{A}}, & \vec{G}=m \vec{g} \\
\vec{R}_{\mathrm{A}}=m\left(\vec{a}_{\mathrm{C}}-\vec{g}\right), & \vec{g}=-g \cdot \vec{j}
\end{array}
$$

The acceleration $\vec{a}_{\mathrm{C}}$ of the mass center in movable coordinate frame $\mathrm{C} \xi \eta$ attached to the body has the form:

$$
\vec{a}_{\mathrm{C}}=\vec{a}_{\mathrm{Ct}}+\vec{a}_{\mathrm{Cn}}=-\ddot{\varphi} \rho_{\mathrm{C}} \vec{\lambda}-\dot{\varphi}^{2} \rho_{\mathrm{C}} \vec{\mu}
$$

where $\vec{a}_{\mathrm{Ct}}$ is tangential and $\vec{a}_{\mathrm{Cn}}$ normal acceleration of the mass center. Expressed in the coordinate frame Axy the acceleration $\vec{a}_{\mathrm{C}}$ is

$$
\begin{aligned}
\vec{a}_{\mathrm{C}} & =\left(-\ddot{\varphi} \rho_{\mathrm{C}} \cos \varphi+\dot{\varphi}^{2} \rho_{\mathrm{C}} \sin \varphi\right) \vec{i}+ \\
& +\left(-\ddot{\varphi} \rho_{\mathrm{C}} \sin \varphi-\dot{\varphi}^{2} \rho_{\mathrm{C}} \cos \varphi\right) \vec{j}
\end{aligned} .
$$

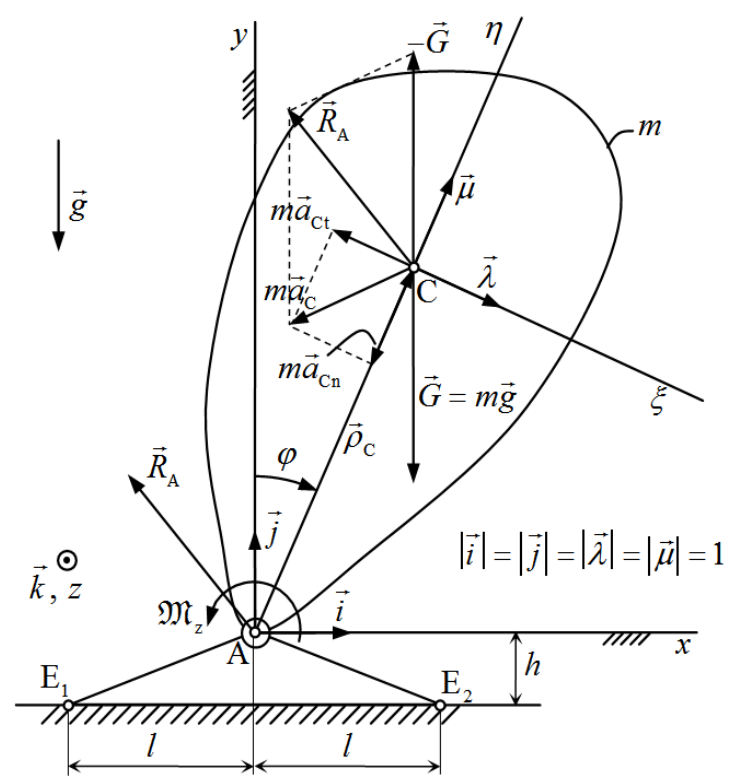

Fig. 2 The rigid body with heavy foot $-\mathrm{a}$ view along $z$-axis

According to (2) the coordinates of the reaction force $\vec{R}_{\mathrm{A}}$ in Axy are

$$
\begin{aligned}
& R_{\mathrm{Ax}}=-m \ddot{\varphi} \rho_{\mathrm{C}} \cos \varphi+m \dot{\varphi}^{2} \rho_{\mathrm{C}} \sin \varphi \\
& R_{\mathrm{Ay}}=-m \ddot{\varphi} \rho_{\mathrm{C}} \sin \varphi-m \dot{\varphi}^{2} \rho_{\mathrm{C}} \cos \varphi+m g
\end{aligned}
$$

In the dynamic balance the foot is at rest, and the center of pressure $\mathrm{P}$ coincides with the zero moment point, which is placed in the support segment $\overline{\mathrm{E}}_{1} \mathrm{E}_{2}=2 l$. In planar case, Fig. 3, the reaction forces of the support are reduced to the resultant $\vec{R}_{\mathrm{p}}$ at the point $P$. The equations of static equilibrium of the foot are given by

$$
\left.\begin{array}{c}
\vec{R}_{\mathrm{P}}-\vec{R}_{\mathrm{A}}+m_{\mathrm{f}} \vec{g}=\vec{o} \\
\left(\vec{\rho}_{\mathrm{P}} \times \vec{R}_{\mathrm{P}}\right) \cdot \vec{k}+\left(\vec{\rho}_{\mathrm{C}_{\mathrm{f}}} \times m_{\mathrm{f}} \vec{g}\right) \cdot \vec{k}-\mathfrak{M}_{\mathrm{z}}=0
\end{array}\right\},
$$

which in scalar form are

$$
\begin{gathered}
R_{\mathrm{P} x}=R_{\mathrm{A} x} \\
R_{\mathrm{P} y}=R_{\mathrm{A} y}+m_{\mathrm{f}} g, \\
\mathfrak{M}_{z}=\rho_{\mathrm{P} x} R_{\mathrm{P} y}-\rho_{\mathrm{P} y} R_{\mathrm{P} x}
\end{gathered}
$$

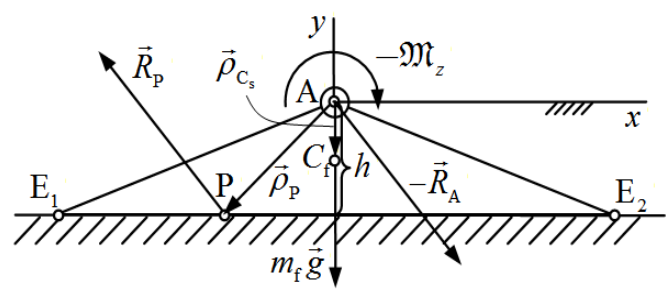

Fig. 3 The foot in static equilibrium 
where $\vec{o}-\quad$ zero vector, $\quad \vec{\rho}_{\mathrm{P}}=\overrightarrow{A P}=\rho_{\mathrm{Px}} \vec{i}+\rho_{\mathrm{Py}} \vec{j}=$ $\rho_{\mathrm{P} x} \vec{i}-h \vec{j}$, and $h$ - height of the foot.

\section{CONDITIONS FOR DYNAMIC BALANCE OF THE SYSTEM}

The conditions for dynamic balance of the system can be defined now in the following way

Condition for dynamic balance In order for the system to be in dynamic balance it is necessary and sufficient that the torque

$$
\mathfrak{M}_{z}=\rho_{\mathrm{P} x} R_{\mathrm{P} y}-\rho_{\mathrm{P} y} R_{\mathrm{P} x}=\rho_{\mathrm{P} x} R_{\mathrm{P} y}+h R_{\mathrm{P} x}
$$

acts at the joint A such that the conditions

$$
\begin{aligned}
& \text { a) } \rho_{\mathrm{P} x} \in(-l, l) \\
& \text { b) } R_{\mathrm{P} y}=R_{\mathrm{Ay}}+m_{\mathrm{f}} g>0
\end{aligned}
$$

are satisfied.

These conditions are equivalent to conditions CDB. They are sufficient for static equilibrium of the foot, but they are not necessary, since the foot can stay immobile even when $\left|\rho_{\mathrm{Px}}\right|=l$ and $R_{\mathrm{Py}}=0$. Therefore, if the foot is at rest, the system need not be in dynamic balance, while if the system is in the dynamical balance then the foot surely is at rest.

Dynamic balance of the system is realized by acting of the controlling torque $\mathfrak{M}_{z}$ such that the conditions (9) are satisfied. Hence, by changing one variable two conditions are to be satisfied which, therefore, are not mutually independent. For instance, if we define the change of the quantity $\rho_{\mathrm{Px}}$ such that the point $\mathrm{P}$ is in the support segment then the controlling torque $\mathfrak{M}_{z}$ and vertical reaction force $R_{\mathrm{Py}}$ are uniquely defined by equations (1), (5) and (7), and so it should be checked whether the reaction force $R_{\mathrm{P} y}$ satisfies the condition (9)b. Analogously, we can define the change of the vertical reaction force that is greater than zero, but it should be checked whether the condition (9)a is satisfied at that change.

We shall determine what conditions must be satisfied by motions of the system in order that condition (9)b is satisfied. According to (1), (5) and (7), we get that condition (9)b follows from

$$
\begin{aligned}
& \text { a) } a \cos ^{2} \varphi+b \cos \varphi+c>0 \\
& \text { b) }\left|\rho_{\mathrm{P} x}\right|<k \rho_{\mathrm{C}}-h>0
\end{aligned} \text {, }
$$

where $a=g, b=k_{\mathrm{m}} g h / \rho_{\mathrm{C}}+k \rho_{\mathrm{C}} \dot{\varphi}^{2}, c=\left(k_{\mathrm{m}} k-1\right) g-h \dot{\varphi}^{2}$, $k=J_{\mathrm{z}} /\left(m \rho_{\mathrm{C}}^{2}\right)>0$, and $k_{\mathrm{m}}=\left(m+m_{\mathrm{f}}\right) / m \geq 1$. If the support segment ${\overline{\mathrm{E}_{1}}}_{2}$ is less than $2\left(k \rho_{\mathrm{C}}-h\right)$ then condition $(10) \mathrm{b}$ will be automatically satisfied if condition (9)a is satisfied. Condition (10)a is satisfied if the state $(\varphi, \dot{\varphi})$ of the system belongs to the region defined by the following conditions
1. For $k \in\left(\left(\frac{h}{2 \rho_{\mathrm{C}}}\right)^{2} k_{\mathrm{m}}+\frac{1}{k_{\mathrm{m}}}, \frac{4}{k_{\mathrm{m}}}\right) \wedge k_{\mathrm{m}}<\frac{2 \rho_{\mathrm{C}}}{h}$

a) $\dot{\varphi}^{2} \in\left[0 \mathrm{rad}^{2} / \mathrm{s}^{2}, k_{\varphi} g / \rho_{\mathrm{C}}\right) \equiv\left[0, k_{\varphi}\right) \cdot g / \rho_{\mathrm{C}}, \forall \varphi$

b) $\dot{\varphi}^{2} \in\left[k_{\varphi}, k_{\mathrm{m}}\right) \cdot g / \rho_{\mathrm{C}} \wedge \cos \varphi \in\left[-1, \lambda_{1}\right) \cup\left(\lambda_{2}, 1\right]$, $(11$

c) $\dot{\varphi}^{2} \geq k_{\mathrm{m}} g / \rho_{\mathrm{C}} \wedge \cos \varphi \in\left[-1, \lambda_{1}\right)$

2. For $k \geq \frac{4}{k_{\mathrm{m}}} \wedge k_{\mathrm{m}}<\frac{2 \rho_{\mathrm{C}}}{h}$
a) $\dot{\varphi}^{2} \in\left[0, k_{\mathrm{m}}\right) \cdot g / \rho_{\mathrm{C}}, \forall \varphi$
b) $\dot{\varphi}^{2} \geq k_{\mathrm{m}} g / \rho_{\mathrm{C}} \wedge \cos \varphi \in\left[-1, \lambda_{1}\right)$,

where $\lambda_{1}$ and $\lambda_{2},-1<\lambda_{1} \leq \lambda_{2}<1$ are roots of the quadratic equation obtained by equalizing left hand-side of inequality (10)a with zero, and

$$
k_{\varphi}=\left[h\left(k_{\mathrm{m}} k-2\right)+2 \sqrt{\left(k_{\mathrm{m}} k-1\right)\left(k^{2} \rho_{\mathrm{C}}^{2}-h^{2}\right)}\right] /\left(k^{2} \rho_{\mathrm{C}}\right) .
$$

All system's motions which satisfy either condition (11) or (12), while condition (10)b is satisfied, will satisfy that the normal reaction force is greater than zero, too. The obtained conditions are not necessary. To find the whole region in the state space where the reaction force $R_{\mathrm{Py}}$ is greater than zero one must consider the case $k_{\mathrm{m}} \geq \frac{2 \rho_{\mathrm{C}}}{h}$ which corresponds to very heavy $\left(m_{\mathrm{f}} \ll<m\right)$ or tall $\left(h \not<\rho_{\mathrm{C}}\right)$ foots or both. The all these foots are not natural, so that we have not considered this case.

It can be seen that keeping the system in dynamic balance depends on its geometrical $h, l$, kinematical $\varphi, \dot{\varphi}$ and geometric-dynamical $k, k_{\mathrm{m}}, \rho_{\mathrm{C}}$ characteristics as well as the characteristic $g$ of the environment in which the system performs motion.

Look of the regions defined by conditions (11) is depicted in Fig. 4 for various foot masses and following parameters of the system and environment

$$
\begin{aligned}
& h=0.08 \mathrm{~m}, \quad l<1.22 \mathrm{~m}, \\
& m=70 \mathrm{~kg}, \quad k=1.3, \quad \rho_{\mathrm{C}}=1 \mathrm{~m}, \quad g=9.81 \mathrm{~m} / \mathrm{s}^{2}
\end{aligned}
$$

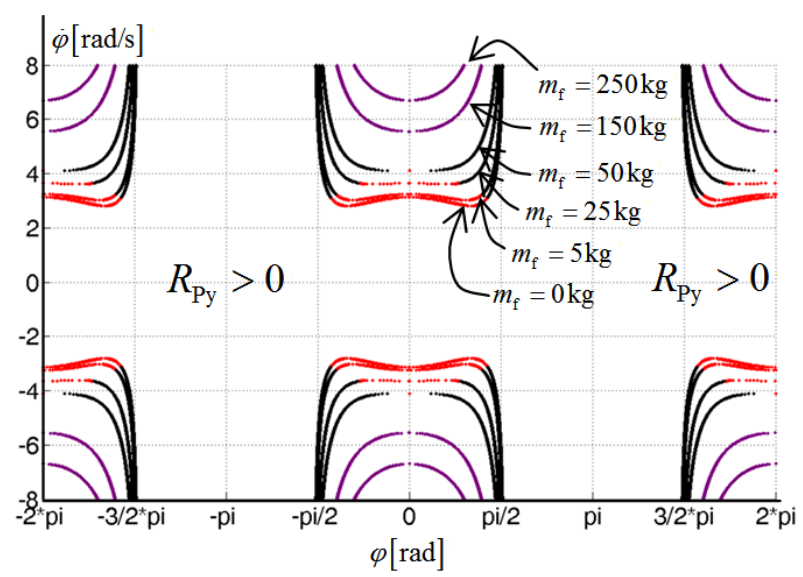

Fig. 4 The regions in the phase space where the vertical reaction force is greater than zero for various foot masses 
As can be seen, the region increases with foot mass increase. The regions corresponding to the foot masses of $150 \mathrm{~kg}$ and $250 \mathrm{~kg}$ were obtained by the condition (11) .2 , while the other regions for lighter foot masses were obtained by the condition (11).1. The figure shows that the regions for real foot masses, which are around or less than $5 \mathrm{~kg}$, are practically identical with the region for the zero foot mass, so that the foot mass does not play important role in dynamical balance of humans. The region border depicted by the red line follows from condition (11).1b, while the region border depicted by the black line follows from condition (11).1c.

Under the action of the torque $\mathfrak{M}_{z}$ defined by (8), the system's motion is described by the following differential equation

$$
\ddot{\varphi}=\frac{\left(g+h \dot{\varphi}^{2}\right) \rho_{\mathrm{C}} \sin \varphi+\rho_{\mathrm{P} x}\left(k_{\mathrm{m}} g-\rho_{\mathrm{C}} \dot{\varphi}^{2} \cos \varphi\right)}{\rho_{\mathrm{C}}\left(k \rho_{\mathrm{C}}+h \cos \varphi+\rho_{\mathrm{P} x} \sin \varphi\right)}
$$

A sufficient condition for the system to be in dynamic balance can now be worded in the following way

Sufficient condition for dynamic balance: In order for the system rigid body with heavy foot to be in dynamic balance it is sufficient that $\rho_{\mathrm{P} x} \in(-l, l)$, the differential equation (14) describes motions of the system, and the phase trajectory belongs to the region defined by conditions (11) and (12)

\section{SIMULATION OF MOTION OF THE SYSTEM IN DYNAMIC BALANCE}

We shall show by simulation of motion of the system in dynamic balance that the system can lose dynamic balance if we only keep the zero moment point inside the support segment, not worrying in which state the system is. We shall also show by simulation that the system can be in dynamic balance not keeping upright posture [4]. The simulations have been done using Runge-Kutta fourth order method with integration step of $0.01 \mathrm{~s}$.

For further consideration, in accordance with defined conditions, the following parameters of the system and environment are adopted

$$
\begin{gathered}
h=0.08 \mathrm{~m}, l=0.13 \mathrm{~m}, m_{\mathrm{f}}=2 \mathrm{~kg} \\
m=70 \mathrm{~kg}, \quad k=1.4, \quad \rho_{\mathrm{C}}=1 \mathrm{~m}
\end{gathered}, \quad g=9.81 \mathrm{~m} / \mathrm{s}^{2} .
$$

Let the system be at the initial instant in the state

$$
\varphi_{0}=-0.1 \mathrm{rad}, \quad \dot{\varphi}_{0}=0 \mathrm{rad} / \mathrm{s},
$$

and let the position of the point $\mathrm{P}$ on the support segment $\overline{\mathrm{E}}_{1} \mathrm{E}_{2}$ be defined by

$$
\rho_{\mathrm{PX}}=0.1 \mathrm{~m}
$$

Obviously, this function satisfies condition (9)a. Then, the time history of the quantities $\varphi, \dot{\varphi}, \rho_{\mathrm{P} x}, R_{\mathrm{P} y}, R_{\mathrm{P} y}$ and $\mathfrak{M}_{z}$ will be

As can be seen from the figure, the vertical reaction force changes its sign, and system loses dynamic balance. From the instant when the vertical reaction force changes the sign for the first time, the simulation does not correspond to the real motion of the system, but the motion which the system would perform if the foot was attached to the support. The real motion of the system after the loss of the dynamic balance would perform by separation of the foot from the support vertical upward.
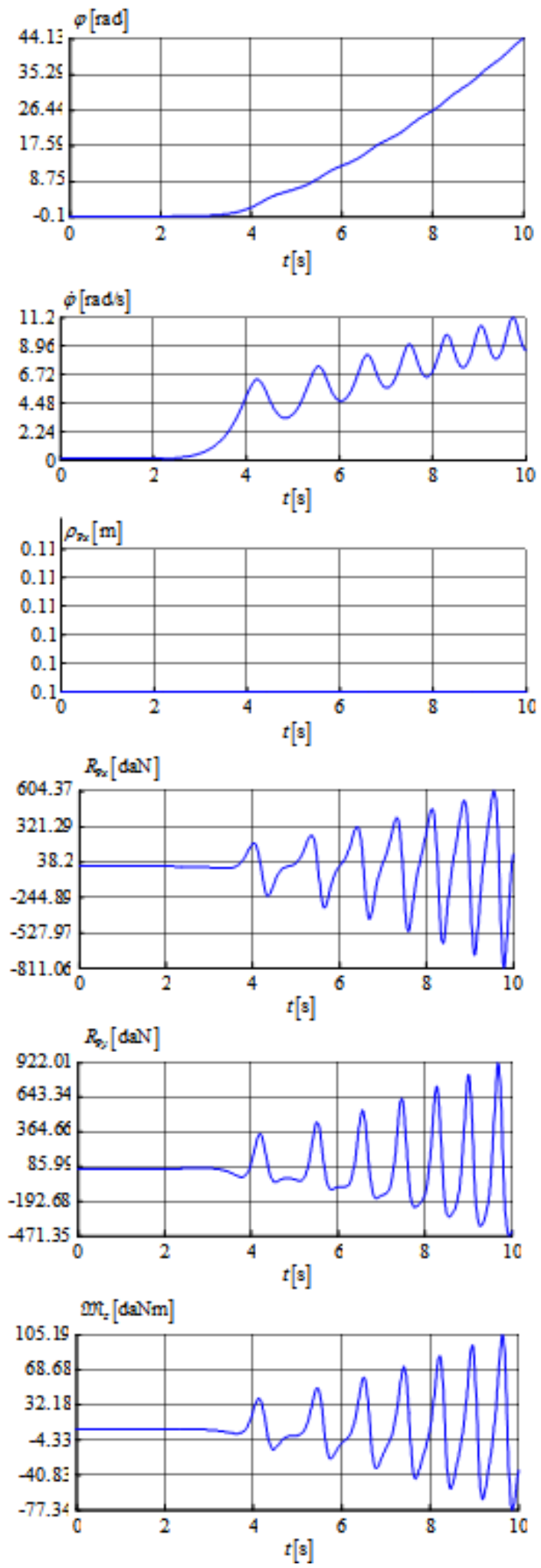

Fig. 5 The time history of quantities $\varphi, \dot{\varphi}, \rho_{\mathrm{P} x}, R_{\mathrm{Py}}, R_{\mathrm{Py}}$ and $\mathfrak{M}_{z}$ - the system loses dynamic balance at the instant when the vertical reaction force changes its sign for the first time 
Let the position of the point $\mathrm{P}$ on the support segment $\overline{\mathrm{E}}_{1} \mathrm{E}_{2}$ now be defined by

$$
\rho_{\mathrm{P} x}=-0.1 \cdot \sin \varphi[\mathrm{m}] .
$$

The following results are obtained.

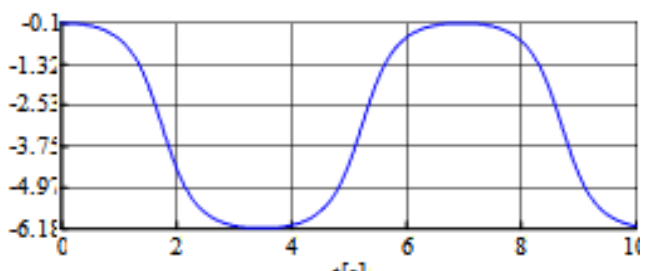

$t[s]$

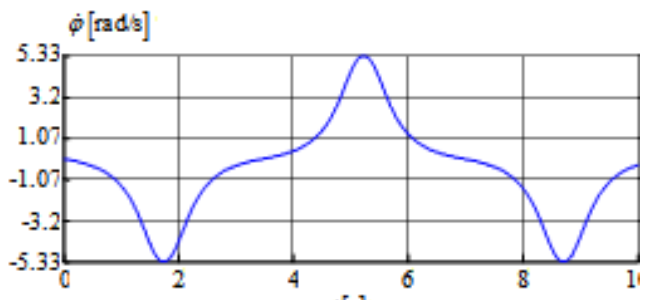

$t[8]$
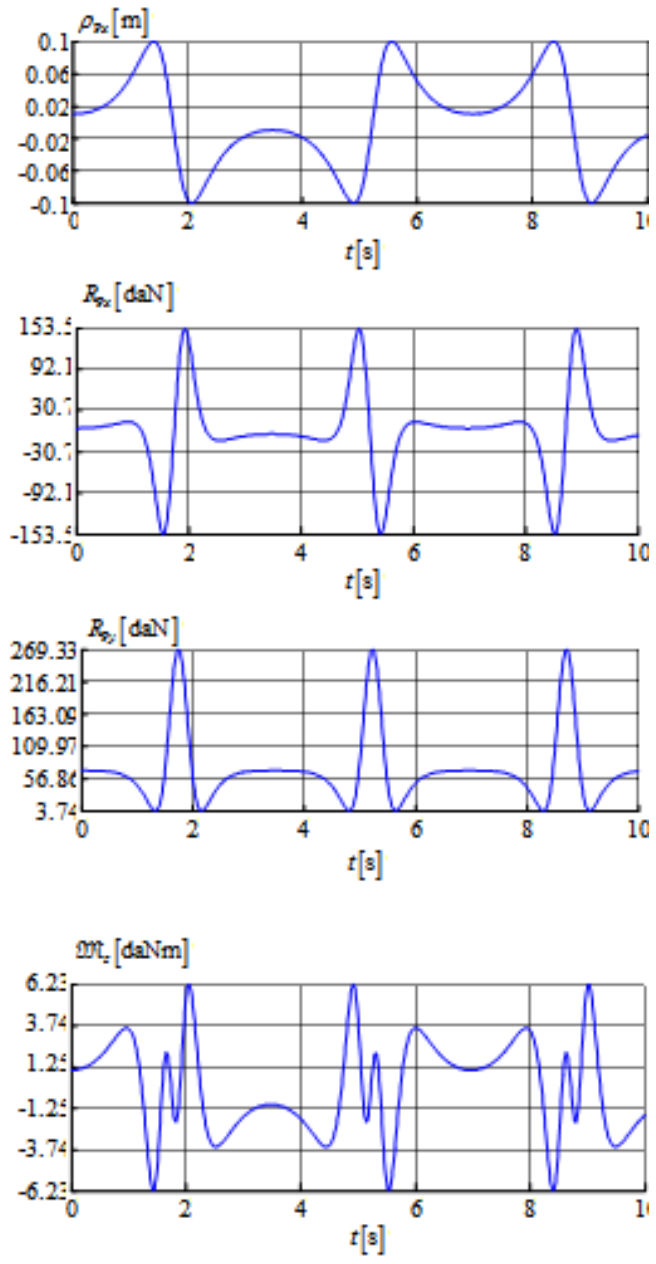

Fig. 6 The time history of quantities $\varphi, \dot{\varphi}, \rho_{\mathrm{P} x}, R_{\mathrm{P} y}, R_{\mathrm{P} y}$ and $\mathfrak{M}_{z}$ - the system is in dynamic balance but does not keep the upright posture

In this case, the system surely falls to the support, although it has been in dynamic balance all the time. Furthermore, if the foot and the support were constructed such that the rigid body could make full circle, the prescribed change (18) of the projection $\mathrm{P}$ of
ZMP would provide system to stay in dynamic balance, since conditions (9) are satisfied.

If the position of the point $\mathrm{P}$ changes according to

$$
\rho_{\mathrm{Px}}=-0.11 \cdot \sin (15 \cdot \varphi)-\frac{0.04}{\pi} \cdot \arctan (50 \cdot \dot{\varphi})[\mathrm{m}](19)
$$

the time histories of quantities $\varphi, \dot{\varphi}, \rho_{\mathrm{Px}}, R_{\mathrm{Px}}, R_{\mathrm{Py}}$ and $\mathfrak{M}_{z}$ are
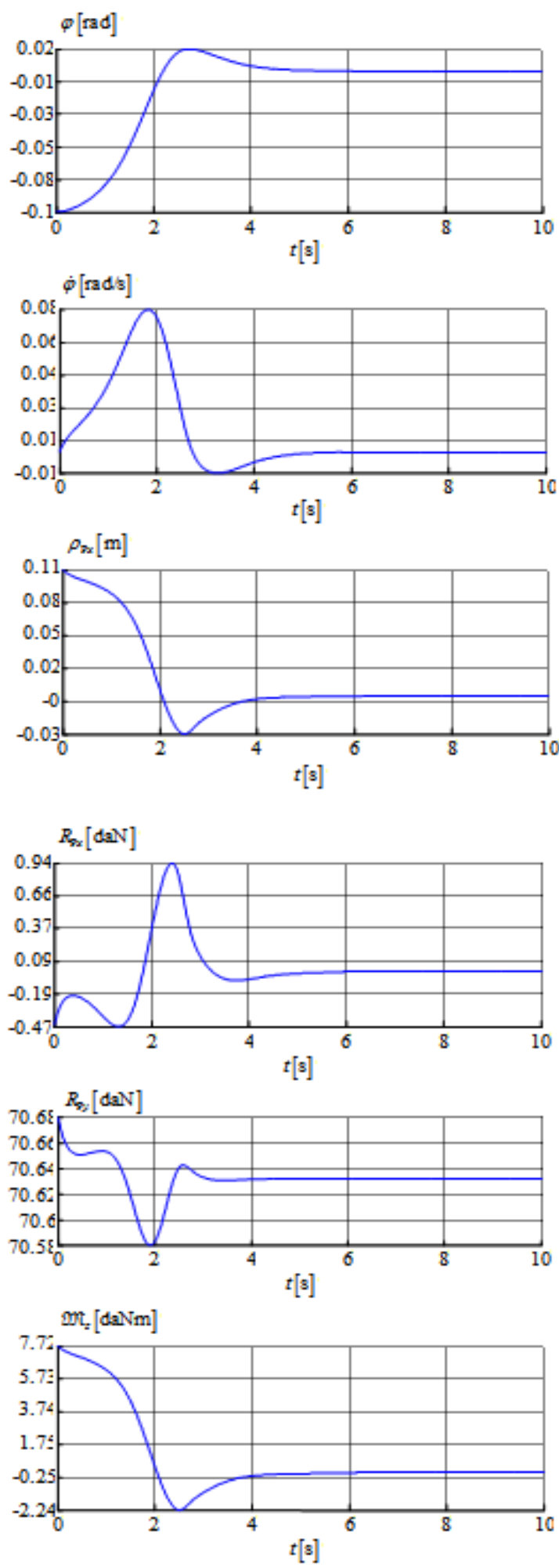

Fig. 7 The time history of quantities $\varphi, \dot{\varphi}, \rho_{\mathrm{P} x}, R_{\mathrm{P} y}, R_{\mathrm{P} y}$ and $\mathfrak{M}_{z}$ - the system keeps upright posture and comes back to the zero state 
It can be seen that the system stays in dynamic balance and comes back to the zero state, while the controlling torque $\mathfrak{M}_{z}$ tends to zero, and the zero moment point tends to the projection of the mass center of the rigid body to the support.

\section{DYNAMIC BALANCE AND UPRIGHT POSTURE OF THE SYSTEM}

Let us consider more precisely the question whether the dynamic balance and upright posture can always be kept.

Let the system be in dynamic balance and have the upright posture at the initial instant. As long as the system is in dynamic balance, its motion is described by differential equation (14). Assume that the dynamical balance is kept such that the angular velocity $\dot{\varphi}$ is not constantly zero nor asymptotically tends to zero. In order that the system may keep the upright posture, the angular velocity $\dot{\varphi}$ must change its sign. Let us consider the instant when $\dot{\varphi}$ is zero and when $\varphi$ is negative. At that instant the acceleration of the rigid body is defined by

$$
\ddot{\varphi}=\frac{\rho_{\mathrm{C}} \sin \varphi+\rho_{\mathrm{Px}} k_{\mathrm{m}}}{\rho_{\mathrm{C}}\left(k \rho_{\mathrm{C}}+h \cos \varphi+\rho_{\mathrm{Px}} \sin \varphi\right)} g
$$

Lest the system continue to fall, the angle $\varphi$ should increase, and, keeping in mind that the angular velocity is zero, the angular acceleration should be positive. The denominator in equation (20) is always positive according to condition (10)b, and for the acceleration to be positive it is necessary and sufficient to be

$$
-\rho_{\mathrm{C}} \sin \varphi<\rho_{\mathrm{Px}} k_{\mathrm{m}}<l k_{\mathrm{m}}
$$

If the projection $-\rho_{\mathrm{C}} \sin \varphi$ of the mass center of the rigid body to $x$-axis is greater than $l k_{\mathrm{m}}$, the system acceleration in dynamic balance cannot become nonnegative and the system continues to fall. An analogous consideration goes when the angle $\varphi$ is positive.

Therefore, if the projection of the mass center to the $x$-axis is out of the interval $\left[-k_{\mathrm{m}} l, k_{\mathrm{m}} l\right]$ the dynamic balance and upright posture cannot be kept simultaneously, since by keeping the dynamic balance the upright posture is inevitably lost.

\section{CONCLUSION}

The mathematical model of a rigid body with heavy foot is given, and the conditions for the system to be in dynamic balance are mathematically defined. Simulations of motion of the system when the system loses dynamic balance although the zero moment point is inside the convex support area, when the system is in dynamic balance but does not keep upright position, and when the system is in dynamic balance, keeps its upright position and tends to the posture which corresponds to the maximum of its potential energy are shown.
It has been shown that dynamic balance implies the static equilibrium of the foot. In addition to being inside the convex support area, the zero moment point cannot change its position in the area arbitrarily since dynamic balance can be violated by separation of the foot from the support vertically upward.

Dynamic balance can be kept even when the system does not keep its upright posture. However, the upright posture of the system in dynamic balance cannot be kept anyway if the vertical projection of the mass center of the rigid body to the support is out of the segment obtained by homothetic increase of the support segment; the center of homothety is the projection of the foot joint to the support, while the homothety ratio is the coefficient $k_{\mathrm{m}}$. For real foot masses the coefficient $k_{\mathrm{m}}$ is approximately 1 , so that the foot mass has practically no influence on dynamic balance of humans.

At the instant when the system loses its dynamic balance, the foot is at the limit of its static equilibrium. Losing the static equilibrium of its foot the system gets additional degrees of freedom. In that case, the number of degrees of freedom is greater than the number of control quantities, and the system is no more completely controllable [5]. Hence, the conditions for dynamic balance of the system can be considered as necessary conditions for its complete controllability [4].

\section{ACKNOWLEDGMENT}

The support of the Ministry of Education, Science and Technological Development of the Republic of Serbia through projects TR 35006,41006 is gratefully acknowledged.

\section{REFERENCES}

[1] Vukobratović M., Borovac B. and Potkonjak V.: Towards a unified understanding of basic notions and terms in humanoid robotics, Robotica, Vol. 25, pp. 87-101, 2007.

[2] Vukobratović M. and Borovac B.: Zero moment point - thirty five years of its life, International Journal of Humanoid Robotics, Vol. 1, No. 1, pp. 157-173, 2004.

[3] Rusov L.: Mechanics - Dynamics (in Serbian), Naučna knjiga, Belgrade, 1994.

[4] Abdallah M. and Goswami A.: Biomechanically motivated two-phase strategy for biped upright balance control, in: Proceedings of the IEEE International Conference on Robotics and Automation, Barcelona, pp.2008-2013, 2005.

[5] Pyatnitskiy Y.: Complete controllability criteria for classes of mechanical systems with bounded controls, J. Appl. Maths Mechs, Vol. 60, No. 5, pp. 703-712, 1996.

[6] Živanović M.M.: Application of ZMP method to keeping dynamic balance of rigid body with light foot - planar case (in Serbian), in: Proceedings of the $53^{\text {rd }}$ ETRAN Conference, Vrnjačka Banja, pp. RO1.3 1-4, 2009. 


\section{УСЛОВИ ЗА ДИНАМИЧКИ БАЛАНС КРУТОГ ТЕЛА С ТЕШКИМ СТОПАЛОМ}

Милош Живановић, Михаило Лазаревић

Описан је модел крутог тела и тешког стопала спојених обртним зглобом у константном гравитационом пољу. Круто тело се креће у вертикалној равни, док тешко стопало лежи на равној, врло храпавој хоризонталној подлози.
Услови за динамички баланс овог система математички су изражени користећи методу тачке нула момента. Показује се да они одређују област у фазном простору у којој стање система треба да буде да би се динамички баланс система одржао. Такође се погодном симулацијом кретања система у динамичком балансу показује да ови услови нису довољни да систем одржи усправан став, већ да су у вези с његовом управљивошћу. Укратко се разматра који су неопходни услови да би овај систем у динамичком балансу задржао усправан став. 